Для цитирования: Никитина В.Б., Рудницкий В.А., Белокрылова М.Ф., Перчаткина О.Э., Костин А.К., Ветлугина Т.П., Аксенов М.М. Прогнозирование формирования органического тревожного расстройства на основе иммунобиологических показателей. Сибирский вестник психиатрии и наркологии. 2020; 3 (108): 28-36. https://doi.org/10.26617/1810-3111-2020-3(108)-28-36

\title{
Прогнозирование формирования органического тревожного расстройства на основе иммунобиологических показателей
}

\section{Никитина В.Б., Рудницкий В.А., Белокрылова М.Ф., Перчаткина О.Э., Костин А.К., Ветлугина Т.П., Аксенов М.М.}

\author{
НИИ психического здоровья, Томский национальньй исследовательский медицинский центр \\ Российской академии наук \\ Россия, 634014, Томск, ул. Алеутская, 4
}

\section{PEЗЮME}

Одну из наиболее значимых проблем современной психиатрии представляют органические непсихотические психические расстройства. Это обусловлено большой их распространенностью как в популяции в целом, так и в психиатрической и общесоматической практике. Цель - выделить иммунобиологические предикторы формирования органического тревожного расстройства. Материал и методы. Проведено комплексное клинико-психопатологическое, экспериментально-психологическое и иммунобиологическое обследование 42 пациентов с непсихотическими психическими расстройствами органического регистра. Согласно МКБ-10, у 25 больных (1-я группа) было диагностировано органическое эмоционально лабильное расстройство (F06.6), у 17 больных (2-я группа) - органическое тревожное расстройство (F06.4). У всех пациентов оценивали уровни личностной и реактивной тревожности. Лабораторное исследование включало фенотипирование иммунокомпетентных клеток по кластерам дифференцировки методом проточной цитометрии и определение концентрации гормонов методом ИФА. Полученные данные были статистически обработаны. Результаты. На основе иммунобиологического подхода разработан способ прогнозирования формирования органического тревожного расстройства. Путем оценки у пациентов с органическим эмоционально лабильным (астеническим) расстройством уровня личностной тревожности, определения в крови иммунологических параметров, концентрации ТТГ и гормонов щитовидной железы и при значениях уровня личностной тревожности более 52 баллов, количества лимфоцитов с рецепторами готовности к апоптозу более 16\%, значении иммунорегуляторного индекса менее 1,3 ед. и концентрации свободного трийодтиронина в сыворотке крови менее 3,6 пмоль/л прогнозируют трансформацию органического эмоционально лабильного (астенического) расстройства, как начального этапа непсихотических психических расстройств органического регистра, в затяжное течение с формированием органического тревожного расстройства. Заключение. Разработанный способ может быть широко использован в медицине и здравоохранении с целью прогноза риска формирования органического тревожного расстройства на более раннем этапе заболевания, позволяет выбрать адекватную стратегию психофармакотерапии, определить психотерапевтические мишени.

Ключевые слова: органическое эмоционально лабильное расстройство, органическое тревожное расстройство, личностная тревожность, иммунитет, иммунорегуляторный индекс, апоптоз, гормоны, трийодтиронин.

\section{ВВЕДЕНИЕ}

Органические непсихотические психические расстройства представляют собой одну из наиболее значимых проблем современной психиатрии. Это обусловлено их большой распространенностью как в популяции в целом, так и в психиатрической и общесоматической практике $[1,2]$. Из всего разнообразия непсихотических психических расстройств органического регистра чаще встречаются органические эмоционально лабильные (астенические) расстройства; наибольшие медицинские и социальные последствия имеют органические тревожные расстройства и органические расстройства личности, которые хуже поддаются лечебным и реабилитационным воздействиям.
Сочетание данных обстоятельств (масштабность распространения, медико-социальное значение и сложности в процессе лечения) определяют значимость представленной проблемы.

Органическое эмоционально лабильное (астеническое) расстройство характеризуется преобладанием в клинической картине астенических проявлений, разных по интенсивности и выраженности эмоциональной неустойчивости, слабодушия, нарастающих когнитивных затруднений. Симптоматика астенического круга полиморфна и включает быструю истощаемость, повышенную утомляемость при физических и умственных нагрузках, слабость, несдержанность, неустойчивые головные боли, головокружение, метеозависимость. 
Клиническое обследование свидетельствует либо о церебрально-органической природе выявленных симптомов, либо о сочетании соматических и церебрально-органических факторов со склонностью к преобладанию в их генезе цереброваскулярных и метаболических нарушений. Данные психические расстройства развиваются постепенно, склонны к прогредиентному течению и носят хронический характер, обычно в поле зрения психиатра попадают уже на стадии нозологически оформленных заболеваний, так как чаще всего довольно поздно диагностируются. При неблагоприятных обстоятельствах астенические расстройства могут иметь склонность к видоизменению основной психопатологической симптоматики, в результате которой появляются и нарастают несвойственные ранее для пациента тревожные состояния, которые постепенно начинают доминировать в клинической картине заболевания, обусловливая формирование органического тревожного расстройства. Негативными сторонами описанной динамики являются изменение медико-социальной характеристики психических расстройств, утяжеление течения болезни, осложняющее взаимодействие больного с представителями медицинских служб, ухудшающее качество жизни больных и дальнейший прогноз.

Таким образом, основой страдания пациента является уже не слабость и эмоциональная нестабильность (которые также обычно присутствуют), а тревога. Клинически на фоне различных других симптомов тревога характеризуется преобладанием выраженного мучительного и субъективно необъяснимого беспокойства, не имеющего достаточных психологических причин. При органической природе заболевания данная тревога связана не с психотравмирующими и социально обусловленными обстоятельствами, а с внутренними патофизиологическими процессами, определяемыми церебрально-органическим процессом. Данная тревога, как правило, не соответствует психосоциальной ситуации и может способствовать возникновению вторичных психосоциальных проблем в связи с неадекватными эмоциями и поведением больного. Снижение памяти и ослабление других когнитивных функций вследствие прогрессирования психического расстройства клинически накладываются на выраженную и постепенно нарастающую тревожность, что затрудняет функционирование пациента в социальном и личном пространстве, обусловливает субъективные проблемы в процессе терапии. Больные жалуются на выраженное, стойкое ощущение неопределенности, беспокойство, необоснованное предчувствие беды, нарушения сна и непонимание со стороны окружающих. При клиническом осмотре у таких пациентов наблюдают- ся ускорение речи, суетливость, непродуктивная повышенная социальная активность, обидчивость, конфликтность, сопровождающиеся раздражительностью, полиморфной и изменчивой соматической симптоматикой и вегетативнососудистыми нарушениями. У большинства больных выявляется значительная соматическая отягощенность с преобладанием сосудистых нарушений (ишемическая болезнь сердца, гипертоническая болезнь) и, что встречается реже, эндокринной патологии. Декомпенсация соматических заболеваний усиливается, тревожные проявления при этом труднее поддаются коррекции. Большая часть пациентов сосредотачивается на соматических проблемах, имея склонность игнорировать психиатрическую проблематику, что часто приводит к нарушениям режима лечения вплоть до его преждевременного прекращения.

В научной литературе описана роль биологических, социальных, психологических факторов в развитии неблагоприятного течения органических непсихотических расстройств, среди которых часто выявляются токсикоз беременности и/или неблагополучные роды у матери, тяжелые инфекционные заболевания, перенесенные в раннем детском возрасте черепно-мозговые травмы, наличие в преморбиде неустойчивого личностного радикала, длительная физическая и психоэмоциональная нагрузка, искажение реакции на психофармакотерапию, угнетение $\alpha$-ритма и увеличение амплитуды низкочастотного $\beta$-ритма на ЭЭГ и др. [3, 4].

Ранее нами был разработан способ прогнозирования формирования органического расстройства личности у лиц с органическими эмоционально лабильными расстройствами с использованием иммунологических показателей - количества Тлимфоцитов, лимфоцитов с Fas-рецепторами готовности к апоптозу и уровня мозгоспецифического белка S-100. При содержании количества Tлимфоцитов $\mathrm{CD}^{+}$-фенотипа 51\% и менее, количества лимфоцитов с Fas-рецепторами готовности к апоптозу $\mathrm{CD}^{+} 5^{+}$-фенотипа $25 \%$ и более, наличии уровня мозгоспецифического белка S-100 в сыворотке крови 6,12 нг/мл и более возможно прогнозирование формирования органического расстройства личности на этапе органического эмоционально лабильного расстройства $[5,6]$.

Изучение критериев прогноза затяжного течения и предикторов неблагоприятной динамики в виде трансформации в более тяжелые нозологические формы органических непсихотических расстройств является одной из актуальных задач прикладной и фундаментальной медицины, так как позволяет усовершенствовать как диагностические, так и лечебные и профилактические подходы. 


\section{ЦЕЛЬ ИССЛЕДОВАНИЯ}

Выделить иммунобиологические предикторы формирования органического тревожного расстройства.

\section{МАТЕРИАЛЫ И МЕТОДЫ}

Проведено комплексное клинико-психопатологическое, экспериментально-психологическое и иммунобиологическое обследование 42 лиц, проходивших курс стационарного лечения в первом клиническом психиатрическом отделении клиники НИИ психического здоровья Томского НИМЦ.

Диагностическая оценка проводилась по основным клиническим критериям МКБ-10. У 25 больных (1-я группа) было диагностировано органическое астеническое расстройство (F06.6), у 17 больных (2-я группа) - органическое тревожное расстройство (F06.4). Общая группа пациентов включала 15 мужчин и 27 женщин. Сред-

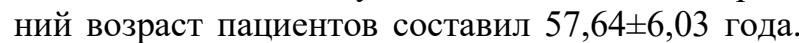
От всех пациентов было получено информированное согласие на участие в исследовании.

Уровень тревожности определяли по шкале реактивной (ситуативной) и личностной тревожности Спилбергера, адаптированной Ю.Л. Ханиным [7].

В качестве материала для биологических исследований была использована венозная кровь. Забор крови осуществляли из локтевой вены утром натощак с использованием стерильной системы однократного применения Vacutainer (производитель Becton Dickinsonand Company, USA).

Лабораторные методы включали фенотипирование поверхностных рецепторов иммунокомпетентных клеток методом проточной цитометрии системы Facs Calibur (производитель Becton Dickinson, USA) с использованием серии реагентов BD Multitest ${ }^{\mathrm{TM}}$ (производитель Becton Dickinson, USA). Определяли $\mathrm{CD}^{+}{ }^{+} \mathrm{CD} 19^{-}$(Т-лимфоциты), $\mathrm{CD}^{+} \mathrm{CD}^{+} \quad$ (Т-хелперы/индукторы $), \quad \mathrm{CD} 3^{+} \mathrm{CD}^{+}$ (цитотоксические Т-лимфоциты), $\mathrm{CD} 3{ }^{-\mathrm{CD}} 19^{+}(\mathrm{B}-$ лимфоциты), $\mathrm{CD} 3{ }^{-} \mathrm{CD} 16^{+} \mathrm{CD}^{+} 6^{+}$(натуральные клетки-киллеры, NK-клетки), $\mathrm{CD}^{+}{ }^{+} \mathrm{CD} 95^{+}$(клетки, экспрессирующие Fac-рецепторы готовности к апоптозу); рассчитывали иммунорегуляторный индекс $-\mathrm{CD}^{+} \mathrm{CD}^{+} / \mathrm{CD}^{+} \mathrm{CD}^{+}$. Определяли концентрацию тиреотропного гормона (ТТГ) и гормонов щитовидной железы - свободные фракции трийодтиронина (Т3) и тироксина (Т4) в сыворотке крови на автоматическом ИФА-анализаторе (Lazurite, Dynex Technologies, Inc., USA) в соответствии с инструкцией по применению наборов реактивов для иммуноферментного определения гормонов в сыворотке крови (ЗАО «Вектор-Бест», п. Кольцово, Новосибирская обл., Россия). В качестве контроля были использованы психологические и иммунобиологические данные 75 практически здоровых лиц, соответствующих по полу и возрасту пациентам с органическими расстройствами.

Статистический анализ включал использование пакетов STATISTICA (версия 12.0 для Windows). Анализ количественных данных проводили путем сравнения независимых выборок с помощью U-критерия Манна-Уитни. Критический уровень значимости принимался равным 0,05. Описательная статистика и табличные данные представлены в виде $\mathrm{M} \pm \mathrm{m}$, где $\mathrm{M}$ - среднее арифметическое, $\mathrm{m}$ - стандартная ошибка среднего арифметического.

\section{РЕЗУЛЬТАТЫ И ОБСУЖДЕНИЕ}

Данные экспериментально-психологического обследования пациентов и здоровых лиц представлены в таблице 1.

Анализ результатов свидетельствует, что в группе пациентов с органическим тревожным расстройством по сравнению с пациентами с органическим эмоционально лабильным (астеническим) расстройством и здоровыми лицами выявлен достоверно высокий уровень личностной тревожности - 52,47 $\pm 1,55$ балла $(\mathrm{p}=0,000595$ и $\mathrm{p}=0,000001$ соответственно). Показатели реактивной тревожности у пациентов с тревожной симптоматикой выше контрольных значений, но ниже, чем у лиц с астеническими расстройствами. Однако полученные различия в обоих случаях не достигают уровня достоверной значимости.

Т а б л и ц а 1. Уровни реактивной и личностной тревожности у пациентов с непсихотическими психическими расстройствами органического регистра и здоровых лиц $(\mathrm{M} \pm \mathbf{m})$

\begin{tabular}{|c|c|c|c|c|}
\hline \multirow[t]{2}{*}{ Показатель } & \multicolumn{3}{|c|}{ Группа обследованных пациентов } & \multirow[b]{2}{*}{$\mathrm{p}_{2}$} \\
\hline & $\begin{array}{c}\text { Здоровые } \\
\text { лица }(\mathrm{n}=75)\end{array}$ & $\begin{array}{c}\text { 1-я группа } \\
\text { Органическое эмоционально } \\
\text { лабильное расстройство }(\mathrm{n}=25)\end{array}$ & \begin{tabular}{|c|} 
2-я группа \\
Органическое тревожное \\
расстройство $(n=17)$
\end{tabular} & \\
\hline $\begin{array}{c}\text { Реактивная тревожность, } \\
\text { баллы }\end{array}$ & $37,94 \pm 0,97$ & $\begin{array}{c}42,96 \pm 1,36 \\
\mathrm{p}_{1}=0,003579\end{array}$ & $\begin{array}{c}40,88 \pm 1,77 \\
\mathrm{p}_{1}=0,198762\end{array}$ & 0,369788 \\
\hline $\begin{array}{c}\text { Личностная тревожность, } \\
\text { баллы }\end{array}$ & $37,48 \pm 0,83$ & $\begin{array}{c}42,68 \pm 1,86 \\
\mathrm{p}_{1}=0,003264\end{array}$ & $\begin{array}{c}52,47 \pm 1,55 \\
\mathrm{p}_{1}=0,000001\end{array}$ & 0,000595 \\
\hline
\end{tabular}

П р и м е ч а н и е. Достоверность различий: $p_{1}$ - между пациентами и здоровыми лицами; $\mathrm{p}_{2}-$ между 1-й и 2-й группами пациентов. 
При иммунологическом обследовании (табл. 2) установлено, что обе группы пациентов сопоставимы по большинству исследуемых параметров. При детальном анализе выявлены различия между клиническими группами больных с расстройствами органического регистра. Наиболее значимыми особенностями в группе пациентов с органическим тревожным расстройством по сравнению с пациентами с органическим эмоционально лабильным (астеническим) расстройством являются следующие: до- стоверно более высокое содержание лимфоцитов c Fas-рецепторами готовности к апоптозу $\mathrm{CD}^{+} \mathrm{CD}^{2} 5^{+}$-фенотипа ( $\left.\mathrm{p}=0,000009\right)$; изменения субпопуляционного состава Т-лимфоцитов, проявляющиеся в снижении количества Т-хелперовиндукторов $\quad \mathrm{CD}^{+} \mathrm{CD}^{+}$-фенотипа $\quad(\mathrm{p}=0,025790)$ и повышении содержания цитотоксических Тсупрессоров $\mathrm{CD}^{+} \mathrm{CD}^{+}$-фенотипа $(\mathrm{p}=0,016579)$. Всё это приводило к снижению иммунорегуляторного индекса $-\mathrm{CD}^{+} \mathrm{CD}^{+} / \mathrm{CD}^{+}{ }^{+} \mathrm{CD} 8^{+}(\mathrm{p}=0,003487)$.

Т а б л и ц а 2. Показатели системы иммунитета у пациентов с непсихотическими психическими расстройствами органического регистра и здоровых лиц $(\mathrm{M} \pm \mathrm{m})$

\begin{tabular}{|c|c|c|c|c|}
\hline \multirow[t]{2}{*}{ Показатель } & \multicolumn{3}{|c|}{ Группа обследованных } & \multirow[b]{2}{*}{$\mathrm{p}_{2}$} \\
\hline & $\begin{array}{c}\text { Здоровые } \\
\text { лица }(\mathrm{n}=75)\end{array}$ & $\begin{array}{c}1-я \text { группа } \\
\text { Органическое эмоционально } \\
\text { лабильное расстройство }(\mathrm{n}=25)\end{array}$ & \begin{tabular}{|c|} 
2-я группа \\
Органическое тревожное \\
расстройство $(\mathrm{n}=17)$
\end{tabular} & \\
\hline Лейкоциты, $10^{9} /$ л & $6,64 \pm 0,14$ & $\begin{array}{c}6,48 \pm 0,32 \\
\mathrm{p}_{1}=0,739907\end{array}$ & $\begin{array}{c}6,90 \pm 0,47 \\
\mathrm{p}_{1}=0,532048\end{array}$ & 0,918360 \\
\hline Лимфоциты, \% & $35,36 \pm 0,81$ & $\begin{array}{c}33,53 \pm 1,78 \\
\mathrm{p}_{1}=0,336693\end{array}$ & $\begin{array}{c}37,48 \pm 1,36 \\
\mathrm{p}_{1}=0,174706\end{array}$ & 0,088372 \\
\hline $\mathrm{CD}^{+}{ }^{+} \mathrm{CD} 19^{-}, \%$ & $73,62 \pm 0,94$ & $\begin{array}{c}73,60 \pm 1,47 \\
p_{1}=0,563858\end{array}$ & $\begin{array}{c}71,94 \pm 1,73 \\
p_{1}=0,243232\end{array}$ & 0,465202 \\
\hline $\mathrm{CD}^{+}{ }^{+} \mathrm{CD}^{+}, \%$ & $48,67 \pm 0,83$ & $\begin{array}{c}45,88 \pm 1,57 \\
\mathrm{p}_{1}=0,107841\end{array}$ & $\begin{array}{c}40,23 \pm 1,24 \\
p_{1}=0,000030\end{array}$ & 0,025790 \\
\hline $\mathrm{CD}^{+} \mathrm{CD}^{+}, \%$ & $24,82 \pm 0,85$ & $\begin{array}{c}27,72 \pm 1,52 \\
\mathrm{p}_{1}=0,101043\end{array}$ & $\begin{array}{c}32,29 \pm 1,10 \\
\mathrm{p}_{1}=0,000043\end{array}$ & 0,016579 \\
\hline $\mathrm{CD}^{+}{ }^{+} \mathrm{CD} 4^{+} / \mathrm{CD}^{+}{ }^{+} \mathrm{CD}^{+}{ }^{+}$ & $2,16 \pm 0,09$ & $\begin{array}{c}1,83 \pm 0,16 \\
p_{1}=0,037015\end{array}$ & $\begin{array}{c}1,26 \pm 0,05 \\
\mathrm{p}_{1}=0,000003\end{array}$ & 0,003487 \\
\hline $\mathrm{CD}^{-} \mathrm{CD}^{-} 9^{+}, \%$ & $10,94 \pm 0,49$ & $\begin{array}{c}13,36 \pm 0,75 \\
\mathrm{p}_{1}=0,031731\end{array}$ & $\begin{array}{c}13,65 \pm 1,29 \\
\mathrm{p}_{1}=0,006965\end{array}$ & 0,827576 \\
\hline $\mathrm{CD}^{-}{ }^{-} \mathrm{CD} 16^{+} \mathrm{CD}^{2} 6^{+}, \%$ & $13,09 \pm 0,69$ & $\begin{array}{c}13,04 \pm 1,11 \\
p_{1}=0,339229\end{array}$ & $\begin{array}{c}14,41 \pm 1,51 \\
\mathrm{p}_{1}=0,811254\end{array}$ & 0,489018 \\
\hline $\mathrm{CD}^{+} \mathrm{CD}^{2} 5^{+}, \%$ & $4,77 \pm 0,21$ & $\begin{array}{c}7,24 \pm 0,83 \\
\mathrm{p}_{1}=0,004774\end{array}$ & $\begin{array}{c}15,94 \pm 1,50 \\
\mathrm{p}_{1}=0,000001\end{array}$ & 0,000009 \\
\hline
\end{tabular}

П р и м е ч а н и е. Достоверность различий: $\mathrm{p}_{1}-$ между пациентами и здоровыми лицами; $\mathrm{p}_{2}-$ между 1-й и 2-й группами пациентов.

По результатам гормонального исследования (табл. 3) в группе пациентов с тревожными расстройствами выявлена достоверно низкая концентрация свободной фракции трийодтиронина (Т3) по сравнению с пациентами с ведущей астенической симптоматикой $(p=0,007132)$ и здоровыми лицами $(\mathrm{p}=0,000001)$. Средние концентрации ТТГ и свободного Т4 у пациентов с органическими тревожными расстройствами не отличались от таковых показателей у пациентов с органическим эмоционально лабильным расстройством и у здоровых лиц контрольной группы.

Т а б л и ц а 3. Гормональные показатели у пациентов с непсихотическими психическими расстройствами органического регистра и здоровых лиц $(\mathrm{M} \pm \mathrm{m})$

\begin{tabular}{|c|c|c|c|c|}
\hline Показатель & \multicolumn{3}{|c|}{ Группа обследуемых пациентов } & 2-я группа \\
\cline { 2 - 5 } & $\begin{array}{c}\text { Здоровые } \\
\text { лица }(\mathrm{n}=75)\end{array}$ & $\begin{array}{c}\text { 1-я группа } \\
\text { Органическое эмоционально } \\
\text { лабильное расстройство }(\mathrm{n}=25)\end{array}$ & $\begin{array}{c}\text { Органическое тревожное } \\
\text { расстройство }(\mathrm{n}=17)\end{array}$ & $\mathrm{p}_{2}$ \\
\hline ТТГ, мМЕ/л & $2,49 \pm 0,23$ & $2,55 \pm 0,51$ & $2,36 \pm 0,57$ & 0,626349 \\
\hline Т3 св., пмоль/л & $6,44 \pm 0,23$ & $\mathrm{p}_{1}=0,412268$ & $3,56 \pm 0,12$ & 0,007132 \\
\hline Т4 св., пмоль/л & $11,31 \pm 0,20$ & $4,69 \pm 0,37$ & $\mathrm{p}_{1}=0,000001$ & 0,987960 \\
& & $11,27 \pm 0,83$ & $10,81 \pm 0,46$ & 0,979557 \\
\hline
\end{tabular}

П р и м е ч а н и е. Достоверность различий: $p_{1}-$ между пациентами и здоровыми лицами; $\mathrm{p}_{2}-$ между 1-й и 2-й группами пациентов. 
На основе полученных данных нами предложен способ прогнозирования риска формирования органического тревожного расстройства у лиц с органическим эмоционально лабильным (астеническим) расстройством. Прогнозирование осуществляется путем оценки у пациентов уровней реактивной и личностной тревожности, определения в крови иммунологических параметров и концентрации свободных фракций тиреоидных гормонов. При повышении уровня личностной тревожности более 52 баллов, количестве лимфоцитов с рецепторами готовности к апоптозу более $16 \%$, значении иммунорегуляторного индекса менее 1,3 ед. и концентрации свободного трийодтиронина в сыворотке крови менее 3,6 пмоль/л прогнозируют трансформацию органического эмоционально лабильного (астенического) расстройства, как начального этапа непсихотических психических расстройств органического регистра, в затяжное течение с формированием органического тревожного расстройства. На данный способ получен патент на изобретение [8].

Выбор уровня личностной тревожности, значения иммунорегуляторного индекса, количества лимфоцитов, экспрессирующих рецепторы готовности к апоптозу, и концентрации свободной фракции Т3 в качестве прогностических критериев риска формирования органических тревожных расстройств на раннем этапе заболевания определяется тем, что непсихотические психические расстройства органического генеза представляют собой класс состояний, непосредственно обусловленных нарушениями структуры и/или физиологических особенностей мозговой ткани. Наблюдающиеся психопатологические симптомы отражают деструкцию или нарушение обмена мозговых структур, обеспечивающих когнитивные функции (запоминание, воспроизведение), детерминирующие эмоции, мотивацию и поведение. Экологическое неблагополучие, социальные и психологические стрессы, хронические соматические заболевания, перенесенные в анамнезе черепно-мозговые травмы приводят к нарушению проницаемости гематоэнцефалического барьера, расстройствам ликвородинамики и возникновению патологической интероцептивной импульсации, гормониндуцированной активации микроглии, нарушающей функциональное состояние корковых клеток и неспецифических срединных структур мозга, включающих ретикулярную формацию ствола, неспецифические структуры среднего мозга, диэнцефальные отделы и лимбическую систему $[9,10,11]$.

В свою очередь лимбико-диэнцефальная система мозга является центральным отделом регуляции функций иммунологической защиты. Поэтому все изменения этих отделов головного моз- га приводят к дезорганизации деятельности регуляторного аппарата, нарушению нейроиммунной регуляции $[12,13]$. Нарушения нейроиммунного взаимодействия ведут, с одной стороны, к дестабилизации психических функций организма, с другой - к дисбалансу иммунной системы, ослаблению механизмов иммунной защиты, присоединению на этом фоне сопутствующей соматической патологии, осложняющих клиническую картину органических непсихотических расстройств и способствующих их неблагоприятному течению $[14,15]$. В лимфоцитах пациентов с пограничными психическими расстройствами на фоне органических повреждений обнаружено увеличение активности ферментов семейства каспаз - ключевых участников процессов апоптотической гибели клеток. Это свидетельствует об активации апоптоза в лимфоцитах. Апоптотическая гибель лимфоцитов может являться одним из основных звеньев развития патологии у людей с органическими поражениями головного мозга, в первую очередь у пациентов с преобладанием тревожного синдрома [16].

Контроль над биосинтезом тиреоидных гормонов осуществляют ЦНС и гипоталамус. Наибольшее биологическое значение имеет трийодтиронин, который активнее тироксина в 4-5 раз. В течение длительного времени считалось, что Т4 и Т3 в равноправной степени принимают участие в обмене веществ. На периферии Т4 конвертируется (переходит) в Т3 и биологическое действие тиреоидных гормонов более чем на 90-92\% осуществляется за счет Т3 [17, 18, 19]. Любые изменения в содержании гормонов щитовидной железы в организме человека нередко сопровождаются усталостью, нервозностью, эмоциональной лабильностью, недомоганием, тахикардией, что впоследствии приводит к беспокойству и тревоге [20, 21, 22, 23].

Показатель личностной тревожности, которая отражает предрасположенность субъекта к тревоге, нарастает с усилением дезадаптивной симптоматики в процессе социальной адаптации человека к новым условиям жизнедеятельности, что сопровождается появлением достоверных корреляционных взаимосвязей между видом и формой иммунитета и индивидуально-личностными характеристиками. Эти корреляции отражают напряженность функционирования иммунной системы при повышении личностной тревожности [24]. Клиническая картина органических тревожных расстройств имеет сложный полиморфный характер и специфическую синдромальную структуру. При данных расстройствах тревога формируется как ситуативно обусловленная реакция личности на органическое заболевание и его последствия [25]. 


\section{ЗАКЛЮЧЕНИЕ}

Таким образом, психологическими и иммунобиологическими особенностями пациентов с органическим тревожным расстройством являются повышение уровня личностной тревожности, количества лимфоцитов с рецепторами готовности к апоптозу, снижение иммунорегуляторного индекса и свободной фракции сывороточного трийодтиронина, что позволяет рассматривать данные показатели в качестве предикторов риска формирования органического тревожного расстройства на раннем этапе заболевания. Развитие принципиально нового направления может обеспечить как современные биологические перспективы лечения и профилактики, так и позволить сбалансировать медико-психологические программы сопровождения больных данной категории.

\section{КОНФЛИКТ ИНТЕРЕСОВ}

Представленные в настоящей статье материалы не содержат каких-либо потенциальных или явных конфликтов интересов авторов.

\section{ИСТОЧНИК ФИНАНСИРОВАНИЯ}

Исследование осуществлено в соответствии с бюджетным финансированием в рамках комплексной темы НИР «Комплексное исследование клинико-психопатологических закономерностей и патобиологических механизмов формирования и прогредиентности социально значимых психических и поведенческих расстройств с разработкой инновационных методов ранней диагностики, персонализированных стратегий терапии и профилактики», регистрационный номер AAAA-A19119020690013-2 0421-2020-0011.

\section{СООТВЕТСТВИЕ ПРИНЦИПАМ ЭТИКИ}

Исследование с участием людей проведено с соблюдением принципов информированного согласия Хельсинкской декларации Всемирной медицинской ассоциации и одобрено Локальным этическим комитетом при НИИ психического здоровья Томского НИМЦ (протокол № 53 от 01.10.2012 г.).

\section{ЛИТЕРАТУРA/REFERENCES}

1. Бохан Н.А., Гычев А.В., Рахмазова Л.Д., Васильева Н.А. Распространенность непсихотических психических расстройств в Сибирском федеральном округе: взаимосвязь с региональными социально-экономическими трендами развития. Социальная и клиническая психиатрия. 2015; 25(2): 78-82. Bokhan N.A., Gychev A.V., Rakhmazova L.D., Vasilieva N.A. Prevalence of nonpsychotic mental disorders in the Siberian Federal region: relation to regional socioeconomic development trends. Social and Clinical Psychiatry. 2015; 25(2): 78-82 (in Russian).

2. Пакриев С.Г., Пакриева О.А. Распространенность органических психических расстройств в терапевтическом стационаре. Вестник неврологии, психиатрии и нейрохирургии. 2017; 1: 56-61. Раkriev S.G., Pakrieva O.A. Prevalence of organic mental disorders in a general hospital. Bulletin of Neurology, Psychiatry and Neurosurgery. 2017; 1: 56-61 (in Russian).

3. Обеснюк О.А., Обеснюк В.В., Патрин И.П. Неврозоподобные расстройства (клинический и электрофизиологический аспекты) у больных с резидуально-органической недостаточностью головного мозга. Сибирский вестник психиатрии и наркологии. 2011; 2(65): 88-90. Obesnyuk O.A., Obesnyuk V.V., Patrin I.P. Neurosis-like disorders (clinical and electrophysiological aspects) in patients with residual-organic brain impairment. Siberian Herald of Psychiatry and Addiction Psychiatry. 2011; 2 (65): 88-90 (in Russian).

4. Иванова Г.Р., Цыганков Б.Д., Добровольская Ю.В., Гаджиева У.Х. Перспективы психокоррекции тревожных и депрессивных расстройств у пациентов с резидуально-органической недостаточностью центральной нервной системы. Вестник неврологии, психиатрии и нейрохирургии. 2016; 2: 47-54. Ivanova G.R., Tsygankov B.D., Dobrovolskaya Yu.V., Gadzhieva U.Kh. Prospects of psychocorrection for anxiety and depressive disorders in patients with residual-organic deficiency of the central nervous system. Bulletin of Neurology, Psychiatry and Neurosurgery. 2016; 2: 47-54 (in Russian).

5. Патент РФ на изобретение № 2488118/20.07.2013. Бюл. № 20. Ветлугина Т.П., Никитина В.Б., Рудницкий В.А., Семке А.В. Способ прогнозирования формирования органического развития личности. RF patent for invention no. 2488118/20.07.2013. Bulletin no. 20. Vetlugina T.P., Nikitina V.B., Rudnitsky V.A., Semke A.V. Method for predicting the formation of organic personality development (in Russian).

6. Nikitina V., Vetlugina T., Rudnitsky V., Lobacheva O., Perchatkina O., Axenov M. Immunological criteria of prognosis of protracted course of organic disorders. Abstracts of the 26th European Congress of Psychiatry (France, Nice, 3-6 March 2018). European Psychiatry. 2018; 48: 292.

7. Малкина-Пых И.Г. Психосоматика: Справочник практического психолога. М.: Изд-во «Эксмо». 2005: 992. Malkina-Pykh I.G. Psychosomatics: Handbook of Practical Psychologist. Moscow: Eksmo Publishing House. 2005: 992 (in Russian).

8. Патент РФ на изобретение № 2712915/03.02.2020. Бюл. № 4. Никитина В.Б., Рудницкий В.А., Белокрылова М.Ф., Лобачева О.А., Перчаткина О.Э., Аксенов М.М., Бохан Н.А. Способ прогнозирования риска формирования органического тревожного расстройства. RF patent for invention no. 2712915/03.02.2020. Bulletin no. 4. Nikitina V.B., Rudnitsky V.A., Belokrylova M.F., Lobacheva O.A., Perchatkina O.E., Aksenov M.M., Bokhan 
N.A. Method for predicting the risk of developing organic anxiety disorder (in Russian).

9. Лурия А.Р. Основы нейропсихологии: Учебное пособие для студентов вузов. М.: Издательский центр «Академия», 2013: 384. Luria A.R. Fundamentals of Neuropsychology: Study guide for university students. Moscow: Publishing Center "Academy", 2013: 384 (in Russian).

10. Kato T.A., Hayakawa K., Monji A., Kanba S. Missing and Possible Link between Neuroendocrine Factors, Neuropsychiatric Disorders, and Microglia. Front Integr Neurosci. 2013 Jul 15; 7: 53. https://doi.org/10.3389/fnint.2013.00053

11. Tagge C.A., Fisher A.M., Minaeva O.V., Gaudreau-Balderrama A., Moncaster J. A., Zhang X.-L., Wojnarowicz M.W., Casey N., Lu H., Kokiko-Cochran O.N. Concussion, microvascular injury, and early tauopathy in young athletes after impact head injury and an impact concussion mouse model. Brain. 2018 Feb 1; 141(2): 422-458. https://doi.org/10.1093/brain/awx350

12. Крыжановский Г.Н. Дизрегуляционная патология и патологические интеграции в нервной системе. Журнал неврологии и психиатрии им. C.C. Корсакова. 2009; 1: 4-9. Kryzhanovsky G.N. Deregulatory pathology and pathological integration in the nervous system. S.S. Korsakov Journal of Neurology and Psychiatry. 2009; 1: 4-9 (in Russian).

13. Erickson M.A., Banks W.A. Neuroimmune Axes of the Blood-Brain Barriers and Blood-Brain Interfaces: Bases for Physiological Regulation, Disease States, and Pharmacological Interventions. Pharmacol Rev. 2018 Apr; 70(2):278-314. https://doi.org/10.1124/pr.117.014647

14. Никитина В.Б., Ветлугина Т.П., Рудницкий В.А., Лобачева О.А., Менявцева Т.А., Аксенов M.М. Иммуноэндокринные факторы в патогенезе непсихотических психических расстройств органического регистра. Психическое здоровье. 2017; 15; 6(133): 21-27. Nikitina V.B., Vetlugina T.P., Rudnitsky V.A., Lobacheva O.A., Menyavtseva T.A., Aksenov M.M. Immunoendocrine factors in pathogenesis of nonpsychotic mental disorders of organic register. Mental Health. 2017; 15; 6(133): 21-27 (in Russian).

15. Клюшник Т.П., Андросова Л.В., Зозуля С.А., Отман И.Н., Никитина В.Б., Ветлугина Т.П. Сравнительный анализ воспалительных маркеров при эндогенных и непсихотических психических расстройствах. Сибирский вестник психиатрии и наркологии. 2018; 2(99): 64-69. Klyushnik T.P., Androsova L.V., Zozulya S.A., Otman I.N., Nikitina V.B., Vetlugina T.P. Comparative analysis of inflammatory markers in endogenous and nonpsychotic mental disorders. Siberian Herald of Psychiatry and Addiction Psychiatry. 2018; 2 (99): 64-69 (in Russian). https://doi.org/10.26617/1810-3111-2018-2(99)-64-69
16. Герасимович Е.С., Яковлев А.А., Дружкова Т.А., Гришкина М.Н., Гехт А.Б., Гуляева Н.В. Активация каспаз в лимфоцитах пациентов с пограничными психическими расстройствами. Биомедицинская химия. 2016; 62 (1): 89-92. Gerasimovich E.S., Yakovlev A.A., Druzhkova T.A., Grishkina M.N., Gekht A.B., Gulyaeva N.V. Activation of caspases in lymphocytes of patients with borderline mental disorders. Biochemistry. 2016; 62 (1): 89-92 (in Russian). https://doi.org/10.18097/PBMC20166201089

17. Ермолаева А.И. Цереброваскулярные расстройства при гипотиреозе. Пенза: Изд-во Пенз. гос. ун-та, 2008: 94. Yermolaeva A.I. Cerebrovascular disorders in hypothyroidism. Penza: Penza State University Press, 2008: 94 (in Russian).

18. Barez-Lypez S., Montero-Pedrazuela A., BoschGarcía D., Venero C., Guadaño-Ferraz A. Increased anxiety, and fear memory in adult mice lacking type 2 deiodinase. Psychoneuroendocrinology. 2017 October; 84: 51-60. https://doi.org/10.1016/j.psyneuen.2017.06.013

19. Fischer S., Ehlert U. Hypothalamic-pituitarythyroid (HPT) axis functioning in anxiety disorders. A systematic review. Depress Anxiety. 2018; 35(1): 98-110. https://doi.org/10.1002/da.22692

20. Тавровская Т.В., Моргунова Т.Б., Тимофеев А.В., Берестенникова Л.Н. Фибрилляция предсердий и тиреотоксикоз. Вестник аритмологии. 2009; 56: 59-80. Tavrovskaya T.V., Morgunova T.B., Timofeev A.V., Berestennikova L.N. Atrial fibrillation and thyrotoxicosis. Arrhythmology Bulletin. 2009; 56: 59-80 (in Russian). http://www.vestar.ru/atts/10739/56p59.pdf

21. Bathla M., Singh M., Relan P. Prevalence of anxiety and depressive symptoms among patients with hypothyroidism. Indian J Endocrinol Metab. 2016 Jul-Aug; 20(4): 468-474. https://doi.org/10.4103/2230-8210.183476

22. Громова Д.О., Вахнина Н.В. Когнитивные нарушения у больных молодого и среднего возраста: диагностика и подходы к терапии. Эффективная фармакотерапия. 2017; 31: 38-47. Gromova D.O., Vakhnina N.V. Cognitive impairment in young and middle-aged patients: diagnosis and approaches to therapy. Effective Pharmacotherapy. 2017; 31: 38-47 (in Russian). https://elibrary.ru/item.asp?id=29970352

23. Yuan L., Luan D., Xu X., Yang Q., Huang X., Zhao S., Zhang Y., Zhou Z. Altered attention networks in patients with thyroid dysfunction: A neuropsychological study. Horm Behav. 2020 May; 121: 104714. https://doi.org/10.1016/j.yhbeh.2020.104714

24. Ветлугина Т.П., Никитина В.Б., Невидимова Т.И., Лобачева О.А., Батухтина Е.И., Стоянова И.Я., Семке В.Я. Система иммунитета и уровень тревожности при адаптации человека к новым условиям жизнедеятельности. Фундаментальные исследования. 2012; 9 (1): 17-21. Vetlugina T.P., Nikitina V.B., Nevidimova T.I., Lobacheva 
O.A., Batukhtina E.I., Stoyanova I.Ya., Semke V.Ya. Immunity system and anxiety level in adaptation of the person to new conditions of vital activity. Basic Research. 2012; 9 (1): 17-21 (in Russian).

25. Панько Т.В., Федченко В.Ю., Каленская Г.Ю., Денисенко М.М. Клинико-психопатологические особенности и принципы лечения органических психических расстройств с симптомами тревоги. Український вісник психоневрології. 2016; 24: 1(86): 124-130. Panko T.V., Fedchenko V.Yu.,
Kalenskaya G.Yu., Denisenko M.M. Clinical and psychopathological features and principles of treatment of organic mental disorders with symptoms of anxiety. Ukrainian Bulletin of Psychoneurology. 2016; 24: 1 (86): 124-130 (in Russian).

Поступила в редакцию 26.05.2020 Утверждена к печати 02.09.2020

Никитина Валентина Борисовна, д.м.н., заведующая лабораторией клинической психонейроиммунологии и нейробиологии. Researcher ID B-9926-2012. Author ID Scopus 55640240200. ORCID ID 0000-0002-1644-770X. Author ID РИНЦ 154172. SРIN-код РИНЦ 3687-7727.

Рудницкий Владислав Александрович, д.м.н., ведущий научный сотрудник отделения пограничных состояний. Researcher ID S-5745-2016. ORCID ID 0000-0003-1089-8793. Author ID РИНЦ 125291. SРIN-код РИНЦ 7358-7174.

Белокрылова Маргарита Федоровна, д.м.н., ведущий научный сотрудник отделения пограничных состояний. Researcher ID S-4150-2016. Author ID Scopus 6506164731. ORCID ID 0000-0003-2497-6684. Аuthor ID РИНЦ 272592. SPIN-код РИНЦ 8197-0723.

Перчаткина Ольга Эрнстовна, к.м.н., зав. отделом координации научных исследований. Researcher ID I-86642017. Author ID Scopus 57202383115. ORCID ID 0000-0001-5538-1304. Author ID РИНЦ 629511. SPIN-код РИНЦ 6299-0859.

Костин Алексей Константинович, научный сотрудник отделения пограничных состояний. Researcher ID J2397-2017. ORCID ID 0000-0002-6006-4853. Author ID РИНЦ 625519. SРIN-код РИНЦ 3564-8249.

Ветлугина Тамара Парфеновна, д.б.н., профессор, ведущий научный сотрудник лаборатории клинической психонейроиммунологии и нейробиологии, руководитель отдела биологической психиатрии и наркологии. Researcher ID C-2144-2012. Author ID Scopus 6603120359. ORCID ID 0000-0003-2068-0931. Аuthor ID РИНЦ 137410. SPIN-код РИНЦ 4237-1873.

Аксенов Михаил Михайлович, д.м.н., проф., руководитель отделения пограничных состояний. Researcher ID I-9478-2017. Author ID Scopus 56897137100. ORCID ID 0000-0002-8949-6596. Author ID РИНЦ 69828. SPINкод РИНЦ 7599-1801.

Никитина Валентина Борисовна, valentina08@sibmail.com

UDC 616.85:66.891.6:612.017.1:616-089.17:577.171.5

For citation: Nikitina V.B., Rudnitsky V.A., Belokrylova M.F., Perchatkina O.E., Kostin A.K., Vetlugina T.P., Aksenov M.M. Predicting the formation of organic anxiety disorder based on immunobiological parameters. Siberian Herald of Psychiatry and Addiction Psychiatry. 2020; 3 (108): 28-36. https://doi.org/10.26617/1810-3111-20203(108)-28-36

\section{Predicting the formation of organic anxiety disorder based on immunobiological parameters}

\section{Nikitina V.B., Rudnitsky V.A., Belokrylova M.F., Perchatkina O.E., Kostin A.K., Vetlugina T.P., Aksenov M.M.}

Mental Health Research Institute, Tomsk National Research Medical Center, Russian Academy of Sciences Aleutskaya Street 4, 634014, Tomsk, Russian Federation

\section{ABSTRACT}

Organic nonpsychotic mental disorders are one of the most significant problems of modern psychiatry. This is due to their high prevalence both in the population as a whole and in psychiatric and general somatic practice. Objective: to identify immunobiological predictors of the formation of organic anxiety disorder. Material and Methods. A 
comprehensive clinical-psychopathological, experimental-psychological and immunobiological examination of 42 patients with nonpsychotic mental disorders of the organic register is carried out. According to ICD-10, 25 patients (group 1) are diagnosed with organic emotionally labile disorder (F06.6), 17 patients (group 2) - organic anxiety disorder (F06.4). The levels of trait and state anxiety are assessed in all patients. The laboratory investigation includes phenotyping of immunocompetent cells on clusters of differentiation by flow cytometry and determination of hormone concentration by ELISA. The data obtained are processed statistically. Results. The method for predicting the formation of organic anxiety disorder is developed based on the immunobiological approach. By assessing the level of trait anxiety in patients with organic emotionally labile (asthenic) disorder, determining the immunological parameters in the blood, the concentration of TSH and thyroid hormones, and with values of the level of trait anxiety more than 52 points, the number of lymphocytes with receptors of readiness for apoptosis of more than $16 \%$, the value of the immunoregulatory index less than 1.3 units. and the concentration of free triiodothyronine in the blood serum of less than $3.6 \mathrm{pmol} / \mathrm{l}$ predict the transformation of organic emotionally labile (asthenic) disorder, as the initial stage of nonpsychotic mental disorders of the organic register, into a protracted course with the formation of organic anxiety disorder. Conclusion. The developed method can be widely used in medicine and health care to predict the risk of the formation of organic anxiety disorder at an earlier stage of the disease, allows choosing an adequate strategy for psychopharmacotherapy, determining targets for psychotherapy.

Keywords: endogenous psychoses, inflammation markers, systemic endotoxinemia, autoantibodies to neuroantigens, endotoxin aggression.

Received May 26.2020

Accepted September 02.2020

Nikitina Valentina B., MD, Head of the Laboratory of Clinical Psychoneuroimmunology and Neurobiology, Mental Health Research Institute, Tomsk National Research Medical Center, Russian Academy of Sciences, Tomsk, Russian Federation. Researcher ID B-9926-2012. Author ID Scopus 55640240200. ORCID iD 0000-0002-1644-770X. Author ID RSCI 154172. SPIN-code RSCI 3687-7727.

Rudnitsky Vladislav A., MD, lead researcher of Borderline States Department, Mental Health Research Institute, Tomsk National Research Medical Center, Russian Academy of Sciences, Tomsk, Russian Federation. Researcher ID S-5745-2016. ORCID iD 0000-0003-1089-8793. Author ID RSCI 125291. SPIN-code RSCI 7358-7174.

Belokrylova Margarita F., MD, lead researcher of Borderline States Department, Mental Health Research Institute, Tomsk National Research Medical Center, Russian Academy of Sciences, Tomsk, Russian Federation. Researcher ID S-4150-2016. Author ID Scopus 6506164731. ORCID iD 0000-0003-2497-6684. Author ID RSCI 272592. SPINcode RSCI 8197-0723.

Perchatkina Olga E., PhD, Head of Research Coordination Department, Mental Health Research Institute, Tomsk National Research Medical Center, Russian Academy of Sciences, Tomsk, Russian Federation. Researcher ID I8664-2017. Author ID Scopus 57202383115. ORCID iD 0000-0001-5538-1304. Author ID RSCI 629511. SPIN-code RSCI 6299-0859.

Kostin Alexey K., PhD, researcher of Borderline States Department, Mental Health Research Institute, Tomsk National Research Medical Center, Russian Academy of Sciences, Tomsk, Russian Federation. Researcher ID J-23972017. ORCID iD 0000-0002-6006-4853. Author ID RSCI 625519. SPIN-code RSCI 3564-8249.

Vetlugina Tamara P., DSc, Prof., lead researcher, Laboratory of Clinical Psychoneuroimmunology and Neurobiology, Head of the Department of Biological Psychiatry and Narcology, Mental Health Research Institute, Tomsk National Research Medical Center, Russian Academy of Sciences, Tomsk, Russian Federation. Researcher ID C-2144-2012. Author ID Scopus 6603120359. ORCID iD 0000-0003-2068-0931. Author ID RSCI 137410. SPIN code RSCI 42371873 .

Aksenov Mikhail M., MD, Prof., Head of Borderline States Department, Mental Health Research Institute, Tomsk National Research Medical Center, Russian Academy of Sciences, Tomsk, Russian Federation. Researcher ID I9478-2017. Author ID Scopus 56897137100. ORCID iD 0000-0002-8949-6596. Author ID RSCI 69828. SPIN-code RSCI 7599-1801.

Nikitina Valentina B., valentina08@sibmail.com 